\title{
Copper recovery from ore by liquid-liquid extraction using aqueous two-phase system
}

\author{
Leandro Rodrigues de Lemos, Igor José Boggione Santos, Guilherme Dias Rodrigues, \\ Luis Henrique Mendes da Silva, Maria C. Hespanhol da Silva*
}

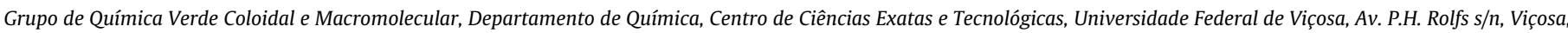
MG 36560-000, Brazil

\section{H I G H L I G H T S}

- A green method for $\mathrm{Cu}(\mathrm{II})$ extraction of ore concentrate was developed.

- Selective separation of $\mathrm{Cu}(\mathrm{II})$ and $\mathrm{Zn}(\mathrm{II}), \mathrm{Co}(\mathrm{II}), \mathrm{Ni}(\mathrm{II}), \mathrm{Cd}(\mathrm{II}), \mathrm{Mn}(\mathrm{II})$, $\mathrm{Al}(\mathrm{III})$ and $\mathrm{Fe}(\mathrm{III})$ was obtained.

- The method is environmental safe, low cost and easy for scale up.

- The liquid-liquid extraction is without use of organic solvent.

\section{A R T I C L E I N F O}

\section{Article history:}

Received 14 March 2012

Received in revised form 13 August 2012

Accepted 14 August 2012

Available online 21 August 2012

\section{Keywords:}

Green chemistry

Copper

Ore

Liquid-liquid extraction

Aqueous two-phase system

\section{G R A P H I C A L A B S T R A C T}

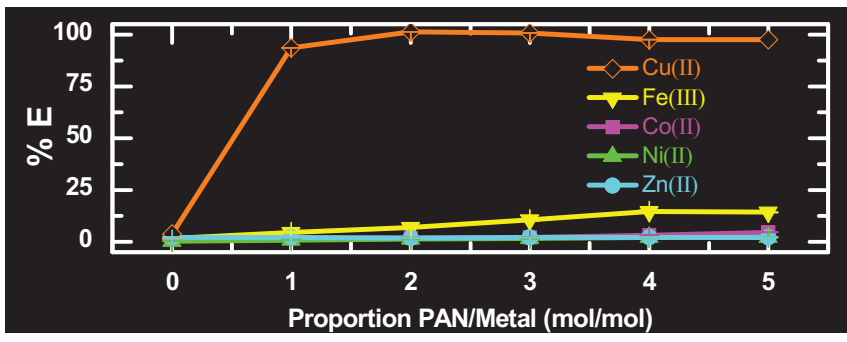

\begin{abstract}
A B S T R A C T
We investigated the extraction behavior of $\mathrm{Cu}(\mathrm{II})$ in the aqueous two-phase system (ATPS) formed by $\left(\mathrm{L} 35+\mathrm{MgSO}_{4}+\mathrm{H}_{2} \mathrm{O}\right)$ or $\left(\mathrm{L} 35+\left(\mathrm{NH}_{4}\right)_{2} \mathrm{SO}_{4}+\mathrm{H}_{2} \mathrm{O}\right)$ in the presence of the extracting agent 1-(2-pyridylazo)2-naphthol (PAN). At pH $=3$ and a PAN concentration of $0.285 \mathrm{mmol} \mathrm{kg}^{-1}$, both ATPS lead to the effective separation of $\mathrm{Cu}$ (II) from other metallic ions ( $\mathrm{Zn}(\mathrm{II}), \mathrm{Co}(\mathrm{II}), \mathrm{Ni}(\mathrm{II})$ and $\mathrm{Fe}(\mathrm{III})$ ). High separation factors range between 1000 and 10,000 were obtained for the extraction of $\mathrm{Cu}(\mathrm{II})$ and concomitant metallic ions. This ATPS was used for the extraction of $\mathrm{Cu}(\mathrm{II})$ from a leached ore concentrate with a extraction percentage of $90.4 \pm 1.1 \%$; other metals were mainly located in the bottom phase.
\end{abstract}

(c) 2012 Elsevier B.V. All rights reserved.

\section{Introduction}

Copper is widely used because it has several essential properties for different technological applications, such as use in electrical materials and construction, transportation, and industrial machinery parts, which are produced at a higher rate every year. At present, there are two main methods employed worldwide to process copper ore for metal production: pyrometallurgical and hydrometallurgical methods.

\footnotetext{
* Corresponding author. Tel.: +55 31 38992175; fax: +55 3138992175 .

E-mail address: mariacarmo@ufv.br (M.C.H. da Silva).
}

The pyrometallurgical method comprises numerous types of shaft and flash technologies, including crushing, grinding, flotation, smelting-refining and electro-refining. The pyrometallurgical method is used for sulfide flotation concentrates, and it is economically feasible for copper rich feeds and large-scale operations [1]. However, this process has several drawbacks, including a high energy consumption and the production of hazardous gases.

Because of an increasing world demand for copper, there is a strong incentive to develop environmentally friendly processes for copper extraction from low-grade ores. Therefore, there is a considerable intensification in the research and development of hydrometallurgical methods. These developments focus on 
by-product and concentrate treatment alternatives to traditional pyrometallurgical methods for the processing of sulfide ores and concentrates, particularly for small-scale production and for the processing of remote metal resources that are not amenable to pyrometallurgy [2]. Hydrometallurgy consists of crushing, leaching, solvent extraction (SE) and electrowinning.

The SE step is very important because it results in the purification and preconcentration of the metal. SE offers a convenient method for the extraction and separation of copper, and SE can be efficiently applied for the recovery of copper from leach liquors and waste solutions using a variety of reagents [3]. SE plants have critical problems that considerably affect the extraction efficiency and selectivity, including crud formation, organic and aqueous phase entrainments, and variable and unpredictable phase separation times in settlers [4]. Furthermore, established SE methods involve organic solvents that are considered hazardous materials because they are detrimental to the environment and harmful to human health [5]. Therefore, it is important to devise novel extraction methods that are cleaner and safer. Hence, the aqueous two-phase system (ATPS) has been introduced as a promising liquid-liquid extraction system for metal separation because it mostly uses water and other nontoxic and nonflammable constituents [6-8].

ATPS is formed under specific thermodynamic conditions when one polymer and one electrolyte are mixed. A phase split results in a polymer-enriched top phase and an electrolyte-enriched bottom phase. Additionally, these systems have a high content of water in both phases [9]. The ATPS has several advantages, including its easy operation, low-cost and the possibility to recycle its components [10]. These systems have been used for the separation, preconcentration, purification and determination of biomolecules [11-14], phenols [15,16], dyes [17] and metallic ions [6-8,18]. Factors such as the $\mathrm{pH}$, the design of the system, the electrolyte composition, the temperature and the extractant concentration strongly affect the partitioning behavior and the separation of analytes [19].

In the described work, we separated copper from other metallic ions using an ATPS formed by a triblock copolymer composed of poly(ethylene oxide) (PEO) and poly(propylene oxide) (PPO), $\mathrm{MgSO}_{4}$ and water at $298 \mathrm{~K}$ in the presence of 1-(2-pyridylazo)2-naphthol (PAN) as an extracting agent. The influence of certain parameters on the metal extraction yield was examined, including the amount of the added extracting agent, the $\mathrm{pH}$ of the system, the nature of the ATPS electrolyte, as well as the separation factor of the copper compared to several other metallic ions (Cd(II), Fe(III), $\mathrm{Al}(\mathrm{III}), \mathrm{Mn}(\mathrm{II}), \mathrm{Ni}(\mathrm{II}), \mathrm{Co}(\mathrm{II})$ and $\mathrm{Zn}(\mathrm{II})$ ). The extraction method was then applied for the efficient extraction and purification of $\mathrm{Cu}(\mathrm{II})$ from the leachate of a copper ore concentrate.

\section{Experimental}

\subsection{Materials and chemicals}

All reagents were of analytical grade quality and were used as received without further purification. The triblock copolymer used in this study was poly(ethylene oxide)-poly(propylene oxide)-poly(ethylene oxide), L35, with an average molar mass $\left(M_{\mathrm{m}}\right)$ of $1900 \mathrm{~g} \mathrm{~mol}^{-1}$ and $50 \%$ ethylene oxide, corresponding to a composition of $(\mathrm{EO})_{11}(\mathrm{PO})_{16}(\mathrm{EO})_{11}$. The triblock copolymer, $\mathrm{H}_{2} \mathrm{SO}_{4}$ and $\mathrm{HNO}_{3}$ were obtained from Aldrich (Milwaukee, WI, USA). $\mathrm{MgSO}_{4} \cdot 7 \mathrm{H}_{2} \mathrm{O},\left(\mathrm{NH}_{4}\right)_{2} \mathrm{SO}_{4}, \mathrm{NaOH}, \mathrm{MnSO}_{4} \cdot \mathrm{H}_{2} \mathrm{O}, \mathrm{ZnSO}_{4}$ and $\mathrm{FeCl}_{3}$ were obtained from VETEC (Duque de Caxias, Rio de Janeiro, Brazil). PAN, $\mathrm{HClO}_{4}, \mathrm{NH}_{4} \mathrm{Al}\left(\mathrm{SO}_{4}\right) \cdot 12 \mathrm{H}_{2} \mathrm{O}, \mathrm{CoCl}_{2}, \mathrm{CdCl}_{2} \cdot \mathrm{H}_{2} \mathrm{O}$, $\mathrm{Ni}\left(\mathrm{CH}_{3} \mathrm{COO}\right)_{2} \cdot 4 \mathrm{H}_{2} \mathrm{O}$ and $\mathrm{CuSO}_{4}$ were purchased from MERCK (Darmstadt, Germany).

\subsection{Equipment}

Deionized water $\left(R \geq 18 \mathrm{M} \Omega \mathrm{cm}^{-1}\right)$ was used throughout the experiments. A Milli-Q II water deionizer (Millipore Corporation) was used for the final purification of the distilled water. The $\mathrm{pH}$ measurements were performed using a glass electrode connected to a digital $\mathrm{pH}$ meter (Digicron Analítica Ltda, Digimed model DM-20). The experiments were performed on an analytical balance (Shimadzu, AY 220) with an uncertainty of $\pm 0.0001 \mathrm{~g}$, and the temperature of the ATPS was adjusted to $25.0 \pm 0.1^{\circ} \mathrm{C}$ with a temperature-controlled water bath (Microquímica, MQBTC 99-20). A hot plate (Fisatom - 752A) and a centrifuge (Thermo Scientific, Heraeus Megafuge 11R) were also used for the experiments. The metal concentrations were measured with a flame atomic absorption spectrometer (VARIAN AA240). The operations conditions were: wavelength $324.8 \mathrm{~nm}$, resolution $0.5 \mathrm{~nm}$, current lamp $4.0 \mathrm{~mA}$, air-acetylene flame (air and acetylene flux rates 3.50 and $1.50 \mathrm{~L} \mathrm{~min}^{-1}$, respectively).

\subsection{Aqueous two-phase system composition}

The aqueous two-phase system formed by $\mathrm{L} 35+\mathrm{MgSO}_{4}+\mathrm{H}_{2} \mathrm{O}$ was prepared by mixing $2.00 \mathrm{~g}$ of a $57.19 \%(\mathrm{~m} / \mathrm{m})$ L35 solution and $2.00 \mathrm{~g}$ of a $19.88 \%(\mathrm{~m} / \mathrm{m}) \mathrm{MgSO}_{4}$ solution [20]. The aqueous two-phase system formed by $\mathrm{L} 35+\left(\mathrm{NH}_{4}\right)_{2} \mathrm{SO}_{4}+\mathrm{H}_{2} \mathrm{O}$ system was prepared mixing $2.00 \mathrm{~g}$ of a $54.22 \%(\mathrm{~m} / \mathrm{m}) \mathrm{L} 35$ solution and $2.00 \mathrm{~g}$ of a $18.71 \%(\mathrm{~m} / \mathrm{m})\left(\mathrm{NH}_{4}\right)_{2} \mathrm{SO}_{4}$ solution [9].

\subsection{Influence of the $\mathrm{pH}$ on extraction behavior}

The partitioning of each metallic ion in the biphasic system was performed to fix the global metal concentration at $0.0950 \mathrm{mmol} \mathrm{kg}-1$. To study the influence of the $\mathrm{pH}$, a PAN/metal ratio of 3 was used. A concentrated metal solution with a concentration of $0.190 \mathrm{mmol} \mathrm{kg}^{-1}$ was prepared in a $19.88 \%(\mathrm{~m} / \mathrm{m})$ $\mathrm{MgSO}_{4}$ solution, and a concentrated PAN solution with a concentration of $0.570 \mathrm{mmol} \mathrm{kg}^{-1}$ was prepared in a $57.19 \%(\mathrm{~m} / \mathrm{m})$ L35 solution. When $2.00 \mathrm{~g}$ of $\mathrm{MgSO}_{4}$ solution is added to $2.00 \mathrm{~g}$ of L35 solution, the metal and PAN final concentration is reduced to a half of initial concentration $\left(0.0950 \mathrm{mmol} \mathrm{kg}^{-1}\right.$ for metal and $0.285 \mathrm{mmol} \mathrm{kg}^{-1}$ for PAN). The $\mathrm{pH}$ of the water used to prepare the $\mathrm{MgSO}_{4}$ and L35 solutions had been previously adjusted. Sulfuric acid was used to adjust the $\mathrm{pH}=1.0,3.0$ or 5.0 and $\mathrm{NaOH}$ was used to adjust $\mathrm{pH}=7.0,9.0$ or 11.0 . In a centrifuge tube $2.00 \mathrm{~g}$ of the metal solution $\left(0.190 \mathrm{mmol} \mathrm{kg}^{-1}\right)$ and $2.00 \mathrm{~g}$ of the PAN solution $\left(0.570 \mathrm{mmol} \mathrm{kg}^{-1}\right)$ were weighed. The tube was manually stirred for $3 \mathrm{~min}$, centrifuged for $15 \mathrm{~min}$ at $3000 \mathrm{rpm}$, and then allowed to settle for $1 \mathrm{~h}$ at $25.0 \pm 0.1^{\circ} \mathrm{C}$. The top phase was then collected, appropriately diluted, and the metal concentration in the top phase was determined with a flame atomic absorption spectrometer (FAAS). The extraction percentage (\%E) of the metallic ions was calculated by Eq. (1).

$\% E=\frac{\left(n_{\mathrm{M}^{m+}}\right)_{\mathrm{Top}}}{\left(n_{\mathrm{M}^{m+}}\right)_{\mathrm{T}}} \times 100$

where $\left(n_{\mathrm{M}^{m+}}\right)_{\text {Top }}$ is the amount (in mol) of metallic ions in the top phase, and $\left(n_{\mathrm{M}^{m+}}\right)_{\mathrm{T}}$ is the total amount of metallic ions in the system.

\subsection{Influence of the amount of PAN on extraction behavior}

An ATPS at $\mathrm{pH}=3.0$ was used to study the influence of the amount of PAN. The procedure for this experiment is similar to what was described in Section 2.3, except that the PAN concentration in the $\mathrm{L} 35$ solution was varied from 0.190 to $0.950 \mathrm{mmol} \mathrm{kg}^{-1}$. 
Table 1

Concentration of predominant metallic ions in the sample ore copper concentrate.

\begin{tabular}{ll}
\hline Metal & Concentration \\
\hline Copper & $29.7 \%(\mathrm{~m} / \mathrm{m})$ \\
Iron & $12.0 \%(\mathrm{~m} / \mathrm{m})$ \\
Nickel & $1.03 \times 10^{3} \mathrm{mg} \mathrm{kg}{ }^{-1}$ \\
Zinc & $326 \mathrm{mg} \mathrm{kg}^{-1}$ \\
Chromium & $134 \mathrm{mg} \mathrm{kg}^{-1}$ \\
Cobalt & $98.8 \mathrm{mg} \mathrm{kg}^{-1}$ \\
\hline
\end{tabular}

\subsection{Influence of the ATPS component nature on extraction behavior}

To study the influence of the ATPS component nature, a PAN concentration of $0.570 \mathrm{mmol} \mathrm{kg}^{-1}$ and a $\mathrm{pH}$ of 3.0 were used. The metal solutions were prepared in a $\mathrm{MgSO}_{4}$ solution or a $\left(\mathrm{NH}_{4}\right)_{2} \mathrm{SO}_{4}$ solution depending on the experiment. The subsequent steps were performed according to what was described in Section 2.3.

\subsection{Copper ore concentrate}

Leaching occurred after incubation at $25^{\circ} \mathrm{C}$ for $8 \mathrm{~h}$ with $1.00 \mathrm{~g}$ of the copper (Mineração Caraíba - Jaguarari, Bahia, Brazil) in $5.00 \mathrm{~mL}$ of $\mathrm{HNO}_{3}(65 \%)$ and $10.0 \mathrm{~mL}$ of concentrated $\mathrm{HClO}_{4}$. The obtained leachate was filtered and transferred to a $1.00 \mathrm{~L}$ flask filled with deionized water. The concentration of the main metals in the resulting solution was then determined with FAAS (Table 1).

\subsection{Copper extraction from the ore leachate and stripping experiments}

Initially, the $\mathrm{pH}$ of the leachate was adjusted to 3.0, resulting in the formation of a precipitate. The precipitate was centrifuged and the concentration of the main metals in the supernatant was determined with a flame atomic absorption spectrometer. The supernatant was used to prepare solutions of $\mathrm{L} 35$ and $\mathrm{MgSO}_{4}$. The PAN solution $\left(14.7 \mathrm{mmol} \mathrm{kg}^{-1}\right)$ was prepared in the $\mathrm{L} 35$ solution. In a tube $3.00 \mathrm{~g}$ of the PAN solution and $3.00 \mathrm{~g}$ of the $\mathrm{MgSO}_{4}$ solution were weighed. The tube was manually stirred for $3 \mathrm{~min}$, centrifuged for $15 \mathrm{~min}$ at $3000 \mathrm{rpm}$, and then allowed to settle for $1 \mathrm{~h}$ at $25.0 \pm 0.1^{\circ} \mathrm{C}$. After each extraction stage the top phase and bottom phase was collected, appropriately diluted, and the metal concentration in both phases were determined with a flame atomic absorption spectrometer.

For both stripping stages of metal ion, $2.00 \mathrm{~g}$ of loaded phase with metal ion (APTS top phase) was taken and contacted with $2.00 \mathrm{~g}$ of ATPS bottom phase added with $\mathrm{HNO}_{3}$ at different concentration, followed by vigorous shaking to reach equilibrium.

\section{Results and discussion}

\subsection{Influence of the $\mathrm{pH}$ on the extraction behavior of metallic ions}

The influence of the $\mathrm{pH}$ on the extraction behavior of $\mathrm{Cu}(\mathrm{II})$, $\mathrm{Zn}(\mathrm{II}), \mathrm{Co}(\mathrm{II})$ and $\mathrm{Ni}(\mathrm{II})$ is shown in Fig. 1. These experiments were performed with the ATPS formed from $\mathrm{L} 35+\mathrm{MgSO}_{4}+\mathrm{H}_{2} \mathrm{O}$ and with a PAN concentration of $0.285 \mathrm{mmol} \mathrm{kg}^{-1}$.

The results showed that all metals are extracted at a minimum efficiency at a pH of 1.0 because of the strong protonation of the PAN molecule at this $\mathrm{pH}$ that hinders its complexation with metals. A high $\mathrm{pH}$ favors the ionization of PAN ( $\mathrm{p} K_{\mathrm{a} 1}=2.9$ and $\left.\mathrm{p} K_{\mathrm{a} 2}=11.6\right)$, which facilitates complexation and increases the extraction yield of $\mathrm{Zn}(\mathrm{II}), \mathrm{Co}(\mathrm{II})$ and $\mathrm{Ni}(\mathrm{II})$. For $\mathrm{Cu}(\mathrm{II})$, the extraction yield initially increases with increasing $\mathrm{pH}$ values because of the ionization of PAN [21]; however, for $\mathrm{pH}$ values greater than 5.0, the amount of

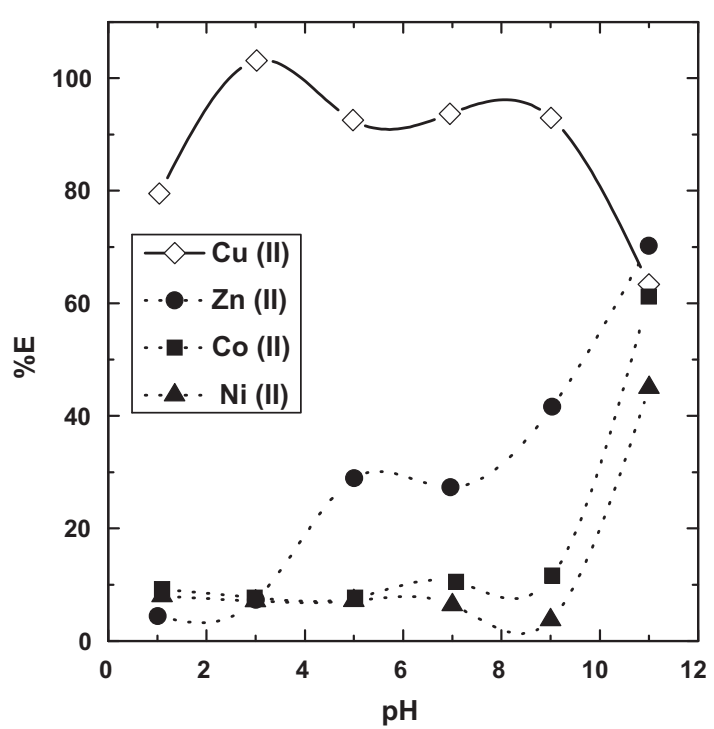

Fig. 1. The effect of the $\mathrm{pH}$ of the ATPS on the \%E of $\mathrm{Cu}(\mathrm{II}), \mathrm{Zn}(\mathrm{II}), \mathrm{Co}(\mathrm{II})$ and $\mathrm{Ni}(\mathrm{II})$ for the $\mathrm{L} 35+\mathrm{MgSO}_{4}+\mathrm{H}_{2} \mathrm{O}$ system with a PAN concentration of $0.285 \mathrm{mmol} \mathrm{kg}^{-1}$.

copper in the top phase decreases. This behavior is because of the increased concentration of hydroxyl groups in the mid-pH range and the subsequent formation of hydroxyl-complexes with $\mathrm{Cu}(\mathrm{II})$, reducing the amount of $\mathrm{Cu}(\mathrm{II})$ that is available to interact with PAN. This effect is less drastic for the other analyzed metals, without affecting the complexation with PAN.

The maximum extraction yields were $103 \pm 2 \%$ for $\mathrm{Cu}$ (II) at $\mathrm{pH}$ 3.0 and $70.2 \pm 1.5 \%, 61.2 \pm 1.3 \%$ and $45.0 \pm 1.2 \%$ for $\mathrm{Zn}(\mathrm{II}), \mathrm{Co}(\mathrm{II})$ and $\mathrm{Ni}(\mathrm{II})$, respectively, at $\mathrm{pH} 12$. However, most interestingly, at pH 3.0 $\mathrm{Cu}(\mathrm{II})$ was completely extracted to the top phase, whereas the other metals were mostly present in the lower phase (\%E $\leq 7.69 \%)$. This is very important for separation processes that require the separation of $\mathrm{Cu}(\mathrm{II})$ from other metallic ions. Therefore, additional studies were performed at this $\mathrm{pH}$.

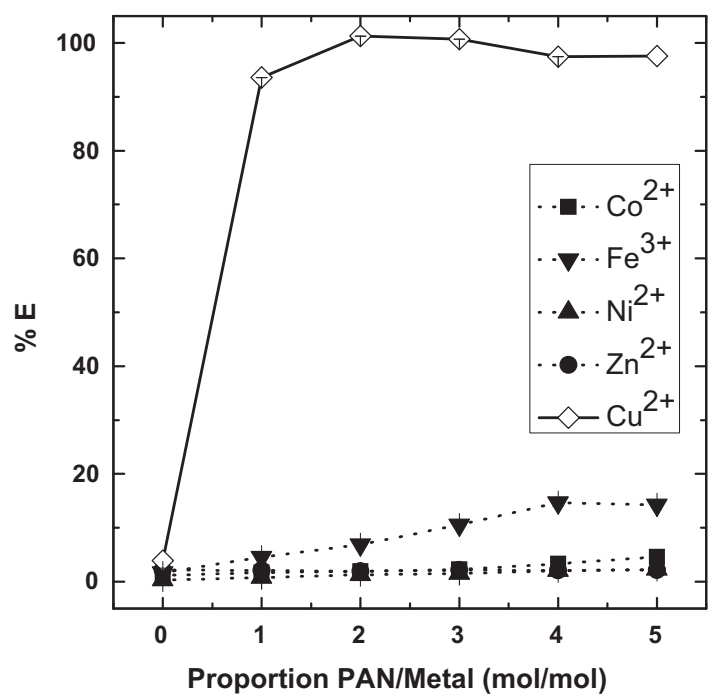

Fig. 2. The effect of the amount of PAN added to the ATPS on the \%E of $\mathrm{Cu}(\mathrm{II}), \mathrm{Zn}(\mathrm{II})$, $\mathrm{Co}(\mathrm{II}), \mathrm{Ni}(\mathrm{II})$ and $\mathrm{Fe}(\mathrm{III})$ for the $\mathrm{L} 35+\mathrm{MgSO}_{4}+\mathrm{H}_{2} \mathrm{O}$ system at $\mathrm{pH}=3$. 


\subsection{Influence of the amount of PAN on the extraction behavior of metallic ions}

Fig. 2 summarizes the \%E of the $\mathrm{Cu}(\mathrm{II}), \mathrm{Co}(\mathrm{II}), \mathrm{Ni}(\mathrm{II}), \mathrm{Zn}(\mathrm{II})$ and $\mathrm{Fe}(\mathrm{III})$ metallic ions added to the $\mathrm{L} 35+\mathrm{MgSO}_{4}+\mathrm{H}_{2} \mathrm{O}$ system at $\mathrm{pH}=3.0$ as a function of the amount of PAN in the top phase.

In the absence of PAN, the metals are mainly concentrated in the bottom phase (Fig. 2) because there are strong interactions between the sulfate (of the salt in the ATPS that is primarily localized in the bottom phase) and the charged species of the metals (Eq. (2)).

$\mathrm{M}_{(\mathrm{aq})}^{m+}+x \mathrm{SO}_{4(\mathrm{aq})}^{2-} \rightleftharpoons \mathrm{M}\left(\mathrm{SO}_{4}\right)_{x(\mathrm{aq})}^{(2 x-m)-}$

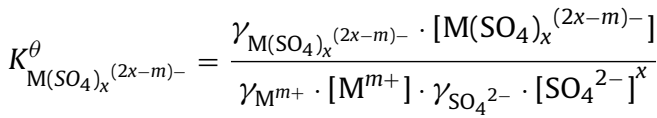

In Eq. (3), $K_{\mathrm{M}\left(\mathrm{SO}_{4}\right)_{x}(2 x-m)-}^{\theta}$ is the standard thermodynamic constant for the formation of the metal-sulfate complex, $\gamma_{\mathrm{M}\left(\mathrm{SO}_{4}\right)_{x}}{ }^{(2 x-m)-}$ is the activity coefficient of the metal-sulfate complex and $\gamma_{\mathrm{M}^{m+}}$ and $\gamma_{\mathrm{SO}_{4}{ }^{2-}}$ are the activity coefficients of the metal and the sulfate, respectively. The stability constant depends on the reaction conditions and the electronic structure of the central metal ion. The metal-sulfate complexes are preferentially formed under standard conditions in the following order: $\mathrm{Cu} \cong \mathrm{Zn} \cong \mathrm{Ni} \cong \mathrm{Co}<\mathrm{Fe}$ [22]. The metal extraction efficiency is inversely proportional to the formation constant of the complex if only the metal-sulfate interaction is considered.

In general, the addition of organic molecules as complexants results in much larger ion distribution coefficients, but this addition constrains the application of ATPS because the complexant must be water soluble [23]. However, the copolymer ATPS enables the use of the water-insoluble extractant, PAN, because the phase enriched in macromolecules is highly hydrophobic due to the presence of macromolecular aggregated formed by a hydrophobic core and a hydrophilic shells.

The addition of PAN to the ATPS initiates complex formation between PAN and the metals. Fig. 2 shows that the addition of PAN results in an increase in \% $E$ for all metals. As the complex between PAN and the metal is formed, the complex moves from the bottom phase to the top phase because it has a specific interaction with the copolymer macromolecules. This PAN-metal complex transfer process results in the formation of additional complexes in the bottom phase via equilibrium displacement. This displacement equilibrium drives the formation of complexes when the concentration of PAN is increased, until a saturation point is reached where additional amounts of PAN do not affect the extraction yield. The extraction of copper in this system is extremely efficient $(\% E \cong 100)$ compared to the extraction of others metals that largely remain in the bottom phase $(\% E \leq 45)$.

\subsection{Influence of the ATPS component nature on the extraction behavior of metallic ions}

The results of the influence of the ATPS salt nature on the extraction behavior of $\mathrm{Cu}(\mathrm{II})$ are shown in Fig. 3. These studies were performed with the ATPS formed by $\mathrm{L} 35+\mathrm{MgSO}_{4}+\mathrm{H}_{2} \mathrm{O}$ or $\mathrm{L} 35+\left(\mathrm{NH}_{4}\right)_{2} \mathrm{SO}_{4}+\mathrm{H}_{2} \mathrm{O}$ and a PAN concentration of $0.285 \mathrm{mmol} \mathrm{kg}^{-1}$ at $\mathrm{pH}=3.0$.

Fig. 3 shows that the ATPS formed by $\mathrm{L} 35+\mathrm{MgSO}_{4}+\mathrm{H}_{2} \mathrm{O}$ is more efficient for the extraction of $\mathrm{Cu}(\mathrm{II})$ at all $\mathrm{pH}$ values. The complex between $\mathrm{Cu}(\mathrm{II})$ and ammonium $(\log K=4.3)$ [22] has a higher formation constant than the complex between $\mathrm{Cu}(\mathrm{II})$ and sulfate $(\log K=2.4)$ [22], thus providing for the ammonium ATPS the least amount of copper for complexation with PAN. Despite its higher efficiency the $\mathrm{L} 35+\mathrm{MgSO}_{4}+\mathrm{H}_{2} \mathrm{O}$ ATPS extracted, in the first

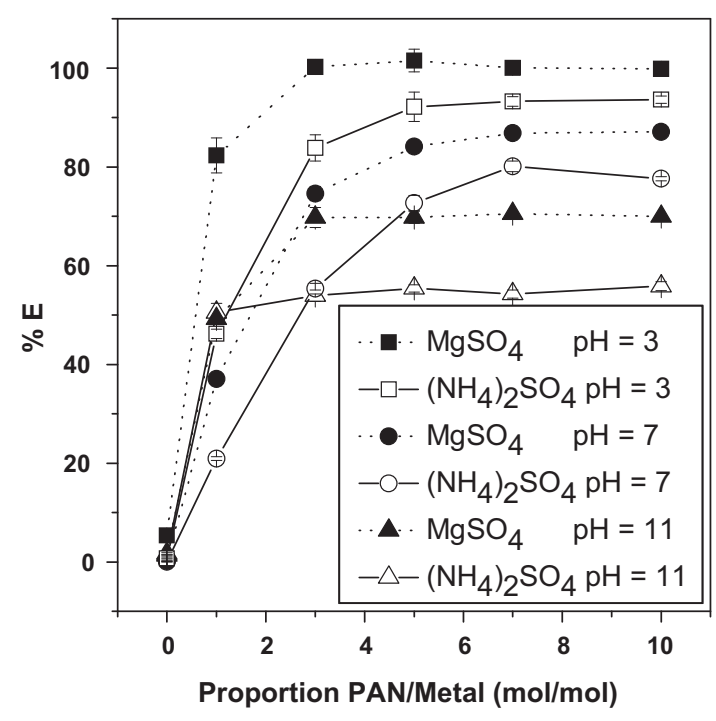

Fig. 3. The effect of ATPS-forming electrolytes $\left(\mathrm{MgSO}_{4}\right.$ or $\left.\left(\mathrm{NH}_{4}\right)_{2} \mathrm{SO}_{4}\right)$ on the \%E of $\mathrm{Cu}(\mathrm{II})$ for different amounts of PAN at $\mathrm{pH}=3.0,6.0$ or 11.0 .

extraction stage, only $82 \%$ (proportion PAN/metal equal to 1.0 ). In order to improve the previous results a second extraction stage was carried out for obtaining $100 \%$ of extraction. This results demonstrated that with only two extraction process this ATPS is capable to produce a complete transference of $\mathrm{Cu}$ (II) from the bottom phase to the top phase.

\subsection{Influence of others metals on the extraction behavior of copper}

Table 2 lists the separation factors $\left(S_{\mathrm{M}, \mathrm{N}}\right)$ for $\mathrm{Cu}(\mathrm{II})$ and other metals present concomitantly in the ATPS $\left(\mathrm{L} 35+\mathrm{MgSO}_{4}+\mathrm{H}_{2} \mathrm{O}\right)$ and a PAN concentration of $0.285 \mathrm{mmol} \mathrm{kg}^{-1}$ at $\mathrm{pH}=3$ in different proportions. The separation factor expresses the efficiency for the separation of two species, $\mathrm{M}$ and $\mathrm{N}$, in liquid-liquid extractions [24], and the value of $S_{\mathrm{M}, \mathrm{N}}$ can be calculated by Eq. (4):

$S_{\mathrm{M}, \mathrm{N}}=\frac{D_{\mathrm{M}}}{D_{\mathrm{N}}}$

where $D_{\mathrm{M}}$ and $D_{\mathrm{N}}$ are the distribution coefficients of species $\mathrm{M}$ and $\mathrm{N}$, respectively. The distribution coefficient of any given species is expressed by Eq. (5):

$D_{\mathrm{M}}=\frac{\% E}{100-\% E}$.

$S_{\mathrm{M}, \mathrm{N}}$ values greater than $10^{3}$ indicate an effective separation between two species.

The separation factor of copper is high compared to the other analyzed metallic ions; the separation factors are greater than $10^{3}$ for most metal concentrations, even reaching values greater than $10^{4}$. This system was extremely efficient for the separation of copper from metals concomitant (Fe, Mn, $\mathrm{Al}, \mathrm{Ni}, \mathrm{Co}$ and $\mathrm{Zn}$ ) present in

Table 2

Separation factors $\left(S_{\mathrm{Cu}, \mathrm{M}}\right)$ of copper $(\mathrm{Cu})$ and several metallic ions (metal).

\begin{tabular}{crrrrrrr}
\hline $\begin{array}{c}\text { Proportion } \\
\text { (metal } / \mathrm{Cu})\end{array}$ & $S_{\mathrm{Cu}, \mathrm{Cd}}$ & $S_{\mathrm{Cu}, \mathrm{Fe}}$ & $S_{\mathrm{Cu}, \mathrm{Al}}$ & $S_{\mathrm{Cu}, \mathrm{Mn}}$ & $S_{\mathrm{Cu}, \mathrm{Ni}}$ & $S_{\mathrm{Cu}, \mathrm{Co}}$ & $S_{\mathrm{Cu}, \mathrm{Zn}}$ \\
\hline 1 & 1320 & 323 & - & 1600 & 1470 & 161 & 481 \\
10 & 2560 & 1980 & 3720 & 5270 & 7040 & 12,000 & 872 \\
50 & 4140 & 25,300 & 2230 & 6100 & 8400 & 27,500 & 979 \\
100 & 3410 & 14,900 & 3020 & 31,800 & 11,500 & 2610 & 482 \\
500 & 3100 & 31,300 & 19,700 & 17,200 & 10,300 & - & 1290 \\
\hline
\end{tabular}




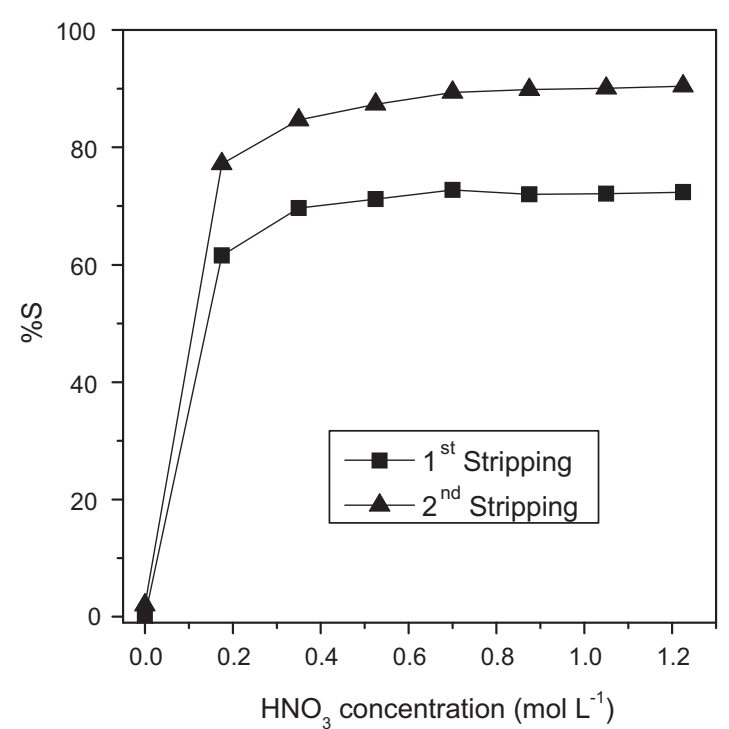

Fig. 4. The stripping of $\mathrm{Cu}^{2+}$ using $\mathrm{HNO}_{3}, \quad[\mathrm{PAN}]=0.570 \mathrm{mmol} \mathrm{kg}^{-1}$, $\left[\mathrm{Cu}^{2+}\right]=0.190 \mathrm{mmol} \mathrm{kg}^{-1}$.

several different proportions. These contaminants are prevalent in different matrices such as copper ore and electronic scrap.

\subsection{Copper extraction from the ore leachate}

To determine the efficiency of the extraction system, ATPS was used for the separation and purification of copper from a copper ore leachate. The composition of the metals in the sample was determined (Table 1 ). The sample was leached, the $\mathrm{pH}$ was adjusted to 3.0, the metallic ion concentration in the supernatant was quantified $\left([\mathrm{Cu}]=306 \mathrm{mg} \mathrm{kg}^{-1}\right.$ and $\left.[\mathrm{Fe}]=54.4 \mathrm{mg} \mathrm{kg}^{-1}\right)$ and the supernatant was used as a solvent for the preparation of the ATPS. The concentration of PAN ( $\left.14.7 \mathrm{mmol} \mathrm{kg}^{-1}\right)$ was three times greater than the concentration of copper in this system.

The \%E of copper was $90.4 \pm 1.1 \%$, demonstrating the efficiency of this extraction technique even with highly concentrated metal samples and in the presence of several contaminating metal species. Iron, the main metal concomitant in this system, was predominantly in the bottom phase and had a low \%E of $16.3 \pm 0.5 \%$.

\subsection{Stripping property}

Although $\mathrm{L} 35+\mathrm{MgSO}_{4}+\mathrm{H}_{2} \mathrm{O}$ with PAN reveals higher extraction abilities for $\mathrm{Cu}^{2+}$, stripping characteristics are important factors for evaluating its potential application. Stripping of $\mathrm{Cu}^{2+}$ was carried out two times using $\mathrm{HNO}_{3}$ solution at $25^{\circ} \mathrm{C}$. To strip the loaded $\mathrm{Cu}^{2+}$, a series of experiments was carried out with varying $\mathrm{HNO}_{3}$ solution concentration from $0.20 \mathrm{~mol} \mathrm{~L}^{-1}$ to $1.2 \mathrm{~mol} \mathrm{~L}^{-1}$. The stripping efficiency $(\% S)$ is defined as follows:

$\% S=\frac{[\mathrm{Cu}]_{\text {Bottom }}}{[\mathrm{Cu}]_{\text {Top }}}$

As shown in Fig. 4, the \%S values of $\mathrm{Cu}^{2+}$ using $\mathrm{L} 35+\mathrm{MgSO}_{4}+\mathrm{H}_{2} \mathrm{O}$ with PAN were $72 \%$ and $90 \%$ in the first and second stripping stages, respectively.

\section{Conclusions}

A new and environmentally friendly ATPS technique was developed for liquid-liquid extraction and purification of $\mathrm{Cu}$ (II) from ores pretreated by hydrometallurgical methods. This technique is compatible with the principles of green chemistry and has a good efficiency and economical viability. The ATPS used in this work consisted of $\mathrm{L} 35+\mathrm{MgSO}_{4}+\mathrm{H}_{2} \mathrm{O}$ or $\mathrm{L} 35+\left(\mathrm{NH}_{4}\right)_{2} \mathrm{SO}_{4}+\mathrm{H}_{2} \mathrm{O}$, and PAN was used as the extracting agent. The extraction efficiency of the metal is affected by the $\mathrm{pH}$, the amount of PAN, the nature of the electrolyte and the presence of metal concomitants. The results showed that all $\mathrm{Cu}(\mathrm{II})$ could be extracted to the top phase at $\mathrm{pH}=3$. At this $\mathrm{pH}$, other metals are mainly present in the lower phase (\%E $\leq 7.69)$; thus, it is possible to separate $\mathrm{Cu}(\mathrm{II})$ at this $\mathrm{pH}$. The addition of PAN to the system results in an increased \%E for all metals, and a PAN concentration of $0.285 \mathrm{mmol} \mathrm{kg}^{-1}$ resulted in the complete extraction of $\mathrm{Cu}$ (II) to the top phase. The ATPS formed by $\mathrm{L} 35+\mathrm{MgSO}_{4}+\mathrm{H}_{2} \mathrm{O}$ showed the highest \% $E$ and the highest separation factor values $\left(S_{\mathrm{Cu}, \mathrm{M}}=1000-10,000\right)$ for $\mathrm{Cu}$ (II) (compared to other metal concomitants). This system was also used for the extraction of copper from a leached ore concentrate. The $\% E$ value of $90.4 \pm 1.1 \%$ demonstrated the efficiency of this extraction technique with a highly complex sample with technological applications.

\section{Acknowledgements}

The authors acknowledge the Fundação de Amparo a Pesquisa do Estado de Minas Gerais (FAPEMIG), Conselho Nacional de Pesquisa e Desenvolvimento Tecnológico (CNPq) and the Instituto Nacional de Ciências e Tecnologias Analíticas Avançadas (INCTAA) for financial support. L.R.L. and G.D.R. acknowledge research fellowships from CAPES and CNPq, respectively. The authors also acknowledge the Mineração Caraíba (Jaguarari, Bahia, Brazil) for providing a sample of the copper concentrate.

\section{References}

[1] K. Rotuska, T. Chmielewski, Growing role of solvent extraction in copper ores processing, Physicochem. Probl. Miner. Process. 42 (2008) 29-36.

[2] S. Agarwal, A.E. Ferreira, S.M.C. Santos, M.T.A. Reis, M.R.C. Ismael, M.J.N. Correia, J.M.R. Carvalho, Separation and recovery of copper from zinc leach liquor by solvent extraction using, Int. J. Miner. Process. 97 (2010) 85-91.

[3] S. Mishra, N. Devi, Extraction of copper(II) from hydrochloric acid solution by Cyanex 921, Hydrometallurgy 107 (2011) 29-33.

[4] C.M. Moreno, J.R. Pérez-Correa, A. Otero, Dynamic modelling of copper solvent extraction mixer-settler units, Miner. Eng. 22 (2009) 1350-1358.

[5] M.C.H. da Silva, L.H.M. da Silva, F.J. Paggioli, A novel micellar medium using triblock copolymer for cobalt determination, Anal. Sci. 21 (2005) 933-937.

[6] G.D. Rodrigues, M.D.H. da Silva, L.H.M. da Silva, F.J. Paggiolli, L.A. Minim, J.S.R. Coimbra, Liquid-liquid extraction of metal ions without use of organic solvent, Sep. Purif. Technol. 62 (2008) 687-693.

[7] V.G. Lacerda, A.B. Mageste, I.J.B. Santos, M.D.H. da Silva, L.H.M. da Silva, Separation of $\mathrm{Cd}$ and $\mathrm{Ni}$ from $\mathrm{Ni}-\mathrm{Cd}$ batteries by an environmentally safe methodology employing aqueous two-phase systems, J. Power Sources 193 (2009) 908-913.

[8] P.D. Patricio, M.C. Mesquita, L.H.M. da Silva, M.C.H. da Silva, Application of aqueous two-phase systems for the development of a new method of cobalt(II), iron(III) and nickel(II) extraction: a green chemistry approach, J. Hazard. Mater. 193 (2011) 311-318.

[9] L.R. de Lemos, I.J.B. Santos, G.D. Rodrigues, G.M.D. Ferreira, L.H.M. da Silva, M.D.H. da Silva, R.M.M. de Carvalho, Phase compositions of aqueous two phase systems formed by L35 and salts at different temperatures, J. Chem. Eng. Data 55 (2010) 1193-1199.

[10] P.D. Patricio, A.B. Mageste, L.R. de Lemos, R.M.M. de Carvalho, L.H.M. da Silva, M.C.H. da Silva, Phase diagram and thermodynamic modeling of PEO + organic salts $+\mathrm{H}_{2} \mathrm{O}$ and $\mathrm{PPO}+$ organic salts $+\mathrm{H}_{2} \mathrm{O}$ aqueous two-phase systems, Fluid Phase Equilib. 305 (2011) 1-8.

[11] L.H. Haraguchi, R.S. Mohamed, W. Loh, P.A. Pessoa-Filho, Phase equilibrium and insulin partitioning in aqueous two-phase systems containing block copolymers and potassium phosphate, Fluid Phase Equilib. 215 (2004) 1-15.

[12] G. Reh, B. Nerli, G. Pico, Isolation of alpha-1-antitrypsin from human plasma by partitioning in aqueous biphasic systems of polyethyleneglycol-phosphate, J. Chromatogr. B 780 (2002) 389-396.

[13] A.M. Azevedo, A.G. Gomes, P.A.J. Rosa, I.F. Ferreira, A.M.M.O. Pisco, M.R. AiresBarros, Partitioning of human antibodies in polyethylene glycol-sodium citrate aqueous two-phase system, Sep. Purif. Technol. 65 (2009) 14-21.

[14] V.M. Andrade, G.D. Rodrigues, R.M.M. de Carvalho, L.H.M. da Silva, M.C.H. da Silva, Aqueous two-phase systems of copolymer L64 + organic salt + water: enthalpic L64-salt interaction and Othmer-Tobias, NRTL and UNIFAC thermodynamic modeling, Chem. Eng. J. 171 (2011) 9-15.

[15] G.D. Rodrigues, L.R. de Lemos, L.H.M. da Silva, M.D.H. da Silva, L.A. Minim, J.S.R. Coimbra, A green and sensitive method to determine phenols in water and 
wastewater samples using an aqueous two phase system, Talanta 80 (2010) 1139-1144

[16] G.D. Rodrigues, L.R. de Lemos, P.D. Patricio, L.H.M. da Silva, M.D.H. da Silva, Aqueous two-phase systems: a new approach for the determination of paminophenol, J. Hazard. Mater. 192 (2011) 292-298.

[17] A.B. Mageste, L.R. de Lemos, G.M.D. Ferreira, M.D.H. da Silva, L.H.M. da Silva, R.C.F. Bonomo, L.A. Minim, Aqueous two-phase systems: an efficient, environmentally safe and economically viable method for purification of natural dye carmine, J. Chromatogr. A 1216 (2009) 7623-7629.

[18] M.D. Hespanhol da Silva, L.H. Mendes da Silva, F.J. Paggioli, J.S. Reis Coimbra, L.A. Minim, Quim. Nova 29 (2006) 1332-1339.

[19] L.R. de Lemos, P.D. Patricio, G.D. Rodrigues, R.M.M. de Carvalho, M.C.H. da Silva, L.H.M. da Silva, Liquid-liquid equilibrium of aqueous two-phase systems composed of poly(ethylene oxide) 1500 and different electrolytes $\left(\mathrm{NH}_{4}\right)_{2} \mathrm{SO}_{4}$, $\mathrm{ZnSO}_{4}$ and $\mathrm{K}_{2} \mathrm{HPO}_{4}$ : experimental and correlation, Fluid Phase Equilib. 305 (2011) 19-24.
[20] M.D.H. da Silva, L.H.M. da Silva, J. Amim, R.O. Guimaraes, J.P. Martins, Liquid-liquid equilibrium of aqueous mixture of triblock copolymers L35 and $\mathrm{F} 68$ with $\mathrm{Na}_{2} \mathrm{SO}_{4}$ or $\mathrm{Li}_{2} \mathrm{SO}_{4}$ or $\mathrm{MgSO}_{4}$, J. Chem. Eng. Data 51 (2006) 2260-2264.

[21] S. Srijaranai, W. Autsawaputtanakul, Y. Santaladchaiyakit, T. Khameng, A. Siriraks, R.L. Deming, Use of 1-(2-pyridylazo)-2-naphthol as the post column reagent for ion exchange chromatography of heavy metals in metals in environmental samples, Microchem. J. 99 (2011) 152-158.

[22] L. Meites, Handbook of Analytical Chemistry, first ed., McGraw-Hill Book Company, New York, 1963, pp. 1-37-1-43.

[23] R.D. Rogers, A.H. Bond, J.H. Zhang, E.P. Horwitz, New technetium-99m generator technologies utilizing polyethylene glycol-based aqueous biphasic systems, Sep. Sci. Technol. 32 (1997) 867-882.

[24] Y.J. Park, D.J. Fray, Separation of zinc and nickel ions in a strong acid through liquid-liquid extraction, J. Hazard. Mater. 163 (2009) 259-265. 